\title{
SITE-SPECIFIC SEQUENCE REPAIR OF CORONAVIRUS DEFECTIVE INTERFERING RNA BY RNA RECOMBINATION AND EDITED RNA
}

\author{
Young-Nam Kim, ${ }^{1}$ Michael M. C. Lai, ${ }^{2}$ and Shinji Makino ${ }^{1}$ \\ ${ }^{1}$ Department of Microbiology, The University of Texas at Austin \\ Austin, Texas 78712 \\ 2 Howard Hughes Medical Institute and Department of Microbiology \\ University of Southern California, School of Medicine \\ Los Angeles, California 90033
}

\section{INTRODUCTION}

Mouse hepatitis virus (MHV), a coronavirus, contains an approximately $31 \mathrm{~kb}$-long genomic RNA $(8,9)$. In MHV-infected cells, seven to eight species of virus-specific subgenomic mRNAs with a 3'-coterminal nested-set structure $(6,10)$ are synthesized; these are numbered 1 to 7 , in decreasing order of size $(6,10)$. The 5'-end of MHV genomic RNA contains a 72- to 77nucleotide-long leader sequence $(5,7,22)$. An identical sequence is found at the 5 '-end of each MHV mRNA species; in each, the leader sequence is fused with the mRNA body sequence, which starts from a consensus sequence at the intergenic sites $(17,21)$.

When the JHM strain of MHV (MHV-JHM) was serially passaged in tissue culture at a high multiplicity of infection, a variety of defective-interfering (DI) RNAs of different sizes were detected (11). Two MHV DI RNAs, DIssE and DIssF were studied in a greter detail $(15,16,19)$. DIssE is $2.3 \mathrm{~kb}$ in length and consists of three noncontiguous genomic regions, comprising the first $0.86 \mathrm{~kb}$ from the 5 '-end, an internal $0.75 \mathrm{~kb}$ from gene 1 , which presumably encodes the RNA polymerase of the virus, and $0.6 \mathrm{~kb}$ from the 3'-end of the parental MHV genome (16). The structure of the $3.6 \mathrm{~kb}$-long DIssF consists of sequences derived from five noncontiguous regions of the genome of nondefective MHV (19). The first four domains (I to IV) from the $5^{\prime}$ end are derived from gene 1 and the 3'-most domain (V) is derived from the 3'-end of genomic RNA. Both DI RNAs contain one large open reading frame (ORF), from which proteins are translated $(16,19)$. Significantly, MHV-A59-derived DI RNAs also contain a large ORF (23). Thus, it seems that the presence of a large ORF is a common feature of MHV DI RNAs, although the biological significance of the ORF is not known. A system has been established in which complete cDNA clones of DIssE and DIssF RNAs were placed downstream of T7 RNA polymerase promoters to generate DIssE and DIssF RNAs capable of efficient replication in the presence of a helper virus. This system has been used for studying MHV RNA replication (14), transcription $(4,13)$ and packaging $(3,19)$.

In the present study, we analyzed a DIssE-derived mutant DI RNA with a one-nucleotide deletion at position 376 from the 5'-end. This one-nucleotide deletion produces an ORF of onetenth the size of the DIssE-specific ORF. The data obtained from this study demonstrated that DI RNA containing this small ORF can replicate at the same efficiency as DI RNA containing the large ORF. During RNA replication, however, DI RNA with the small ORF was replaced with novel DI RNAs containing the large ORF. Of this group, approximately half of the DI RNAs contained sequences created by RNA recombination and the remainder contained sequences in which a specific nucleotide was added at a specific site upstream of the deletion site. 


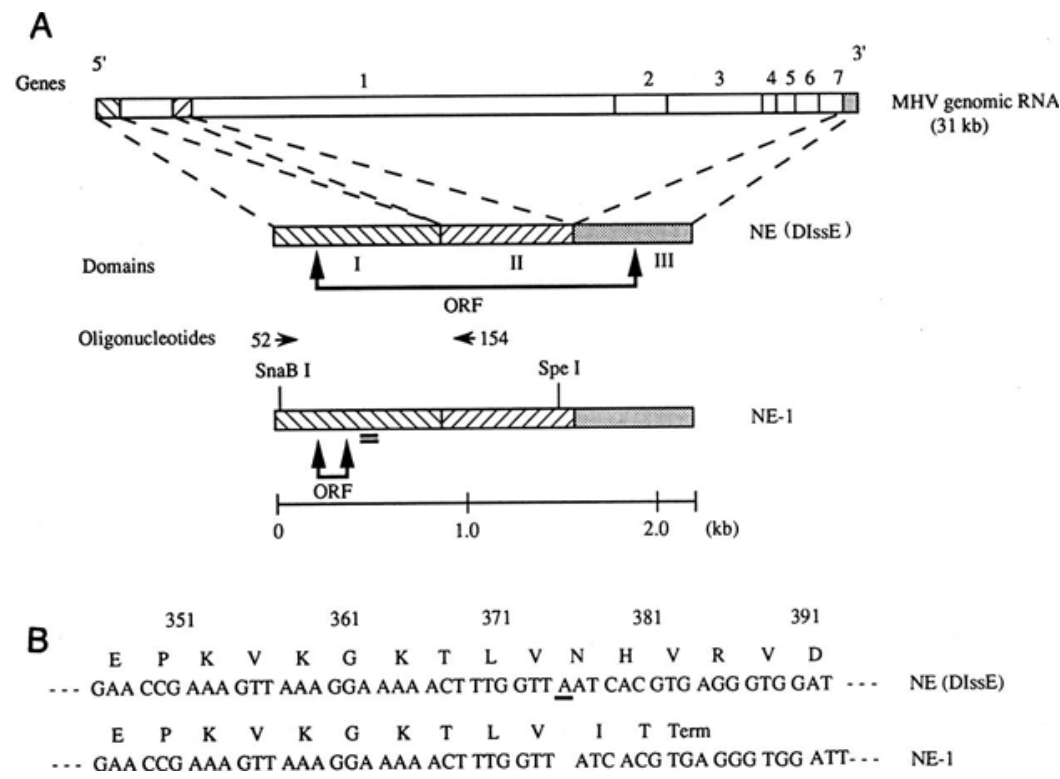

Fig. 1. Diagram of the structure of NE and NE-1. (A) Comparison of the structures of NE, NE-1 and standard MHV genomic RNA. Genes 1 through 7 represent the seven genes of MHV. The locations of the ORFs of NE and NE-1 are shown. The three domains of DIssE-derived DI RNAs (domains I through III) and the oligonucleotides used in the present study are indicated below the diagram of NE. The restriction enzyme sites are indicated above NE-1. The double-underlined region of NE-1 represents the region which is recognized by the anti-p28 antibody (1). (B) The nucleotide and deduced amino acid sequences of the 5'-regions of NE and NE-1. The numbers above these represent the nucleotide positions from the 5'-end of NE DI RNA (13). The $\underline{A}$ underlined in the NE sequence is missing from NE-1.

\section{MATERIALS AND METHODS}

Viruses and cells. The plaque-cloned A59 strain of MHV (MHV-A59) was used as a helper virus. Mouse DBT cells were used for RNA transfection and propagation of viruses.

RNA transcription and transfection. Plasmids were linearized by Xba I digestion and transcribed in vitro with T7 RNA polymerase as described previously (14). The lipofection procedure used for RNA transfection was described previously (13).

Preparation of virus-specific intracellular RNA. Intracellular virus-specific RNA was extracted as described previously (18).

Plasmid construction. Polymerase chain reaction (PCR) products corresponding to the 5 ' end $1.5 \mathrm{~kb}$ region of DIssF were obtained as previously described (19). Two cDNA clones, PCR-1 and PCR-2, were analyzed after the PCR products were cloned; the sequence of PCR-1 has been described (19). The sequence of PCR-2 was identical to that of PCR-1 except for a one-nucleotide deletion at position 376 from the 5 '-end of PCR-2. Two complete DIssE-specific cDNA clones, $\mathrm{NE}$ and NE-1, were constructed by inserting the $1.5 \mathrm{~kb}$ SnaB I-Spe I fragments of PCR-1 and PCR-2, respectively, into the $2.9 \mathrm{~kb}$ SnaB I-Spe I fragment of the DIssE-specific cDNA clone DE5-w4 (14)(Fig. 1).

PCR. For amplification of MHV RNA species, MHV-specific cDNA was first synthesized from intracellular RNA as previously described (16), using as a primer oligonucleotide 154 (5'CTGCTCCCTGGCAACGCC-3'), which binds to positive-stranded MHV DI RNA at nucleotides 952 to 966 from the 5'-end. MHV-specific cDNA was then incubated with oligonucleotide 52 (13), which binds to the leader sequence of negative-stranded MHV RNA, in PCR buffer $(0.05 \mathrm{M}$ $\mathrm{KCl}, 0.01 \mathrm{M}$ Tris hydrochloride [pH 8.3], $0.0025 \mathrm{M} \mathrm{MgCl}_{2}, 0.01 \%$ gelatin, $0.17 \mathrm{mM}$ each of 
dNTPs and 5U of Taq polymerase [Promega]) at $93^{\circ} \mathrm{C}$ for $30 \mathrm{~s}, 55^{\circ} \mathrm{C}$ for $30 \mathrm{~s}$, and $72^{\circ} \mathrm{C}$ for 100 $\mathrm{s}$ for 25 cycles.

Radiolabeling of viral RNAs and agarose gel electrophoresis. Virus-specific RNAs in virus-infected cells were labeled with ${ }^{32} \mathrm{Pi}$ as previously described (18) and separated by electrophoresis on $1 \%$ agarose gels after denaturation with $1 \mathrm{M}$ glyoxal (20).

Labeling of intracellular proteins, immunoprecipitation, and SDS-PAGE. Labeling of intracellular proteins, immunoprecipitation, and SDS-polyacrylamide gel electrophoresis (PAGE) were performed as previously described $(11,19)$.

\section{RESULTS}

During sequence analysis of the cloned PCR products of DIssF DI RNA, we found that one of the cloned PCR products had a single $\underline{A}$-nucleotide deletion at position 376 from the 5 ' end (Fig. 1). Due to this nucleotide deletion, the DI RNA-specific ORF was closed 6 nucleotides downstream of the deletion site. To test the ability of MHV DI RNA containing such a small ORF to replicate in MHV-infected cells, two complete DIssE-derived cDNA clones, NE and NE-1, were constructed. These clones contained identical sequences except that NE-1 had a single $A$ deletion at nucleotide 376, producing a 57-amino-acid-long ORF. In contrast, the ORF of NE encoded 567 amino acids, similar to that of wild-type DIssE (16) (Fig. 1). In vitro-synthesized NE and NE-1 DI RNAs were translated in vitro, and the proteins synthesized were examined directly by SDSPAGE. A 7.5-kDa protein was translated from NE-1 DI RNA; this molecular mass was close to the predicted molecular mass of 7,308. In contrast, an $88-\mathrm{kDa}$ protein was translated from NE DI RNA, and was specifically immunoprecipitated by the anti-p28 antibody (data not shown). The $88-\mathrm{kDa}$ size was consistent with the size of the protein of DIssE (16). These analyses demonstrated that the $7.5-\mathrm{kDa}$ and the $88-\mathrm{kDa}$ proteins were translated from the predicted small ORF of NE-1 DI RNA and the large ORF of NE DI RNA, respectively.
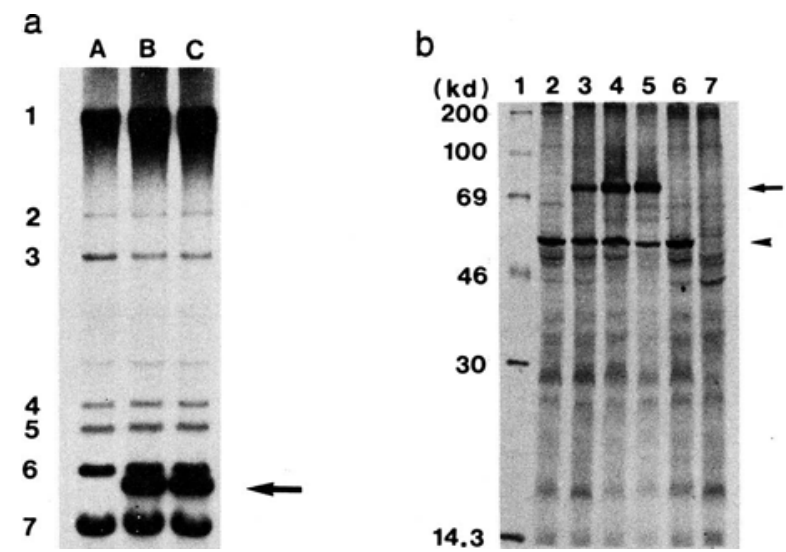

Fig. 2. Replication and protein synthesis by NE and NE-1 DI RNA in passage 0 virus-infected cells and RNAtransfected cells. (a) Agarose gel electrophoresis of MHV-specific intracellular RNAs which were obtained after infection of passage 0 virus samples. ${ }^{32}$ P-labeled virus-specific RNA from DBT cells infected with MHV-A59 (lane A), transfected with NE (lane B) or transfected with NE-1 (lane C) was denatured with glyoxal and electrophoresed on a 1\% agarose gel. Numbers 1 to 7 denote MHV-specific mRNA species. The arrow indicates DI RNAs. (b) SDSPAGE of proteins from DI RNA-replicating cells. DBT cells were infected with MHV-A59 and transfected with in vitro-synthesized NE-1 DI RNA (lane 2), NE DI RNA (lane 3) or mock-transfected (lane 6). DBT cells were infected with passage 0 virus samples obtained from NE-1 DI RNA-transfected cells (lane 4), or from NE DI RNA-transfected cells (lane 5). Lane 7 represents mock-infection and mock-transfection. At $6.5 \mathrm{~h}$ p.i., cultures were labeled with ${ }^{35}$ S ]methionine for $20 \mathrm{~min}$; total cell extracts were then prepared and immunoprecipitated with anti-p28 antibody. The $88-\mathrm{kDa}$ DI-specific protein is indicated by the arrow. The band indicated by the arrowhead represents the nucleocapsid protein of MHV-A59. Lane $1,{ }^{14} \mathrm{C}$-labeled marker proteins. 
To determine if NE-1 DI RNA replicates in MHV-infected cells, in vitro synthesized NE and NE-1 DI RNAs were independently transfected by lipofection into monolayers of DBT cells infected with MHV-A59 helper virus $1 \mathrm{~h}$ prior to transfection. The virus harvested at $16 \mathrm{hr}$ p.i. is referred to as passage 0 virus sample. The passage 0 virus sample was used to infect DBT cells, and the 32P-labeled intracellular RNA species were analyzed by agarose gel electrophoresis. Efficient replication of both NE- and NE-1-derived DI RNAs was observed (Fig. 2a). Next the replication efficiencies of NE DI RNA and NE-1 DI RNA were compared in DI RNA-transfected cells and it was found that there was no significant difference in the efficiency of replication and accumulation between the two DI RNAs (data not shown).

To examine whether NE-1-derived DI RNA still contained the small ORF, metabolic labeling of MHV-specific proteins and subsequent immunoprecipitation of MHV-specific proteins by the anti-p28 antibody were performed. As shown in Fig. 2b, synthesis of the 88-kDa protein was observed in NE DI RNA-transfected, MHV-infected cells as well as in cells infected with NE DI RNA-derived passage 0 virus sample. Surprisingly, the $88-\mathrm{kDa}$ DI-specific protein was also

\begin{tabular}{|c|c|c|c|c|c|c|c|c|c|c|}
\hline 129 & 140 & 180 & 371 & 391 & 411 & 432 & & & & \\
\hline$\underline{\mathbf{A}}$ & $\underline{\mathbf{A}}$ & $\underline{\mathrm{G}}$ & AAGGAAAAACUUUGGUUAAUCAC & $\underline{\mathrm{A}}$ & $\underline{\mathrm{U}}$ & $\underline{\mathrm{U}}$ & MHV-A59 & & & \\
\hline $\mathrm{C}$ & G & $\mathrm{C}$ & AAGGAAAAACUUUGGUUAAUCAC & G & $\mathrm{C}$ & $\mathrm{C}$ & MHV-JHM & & & \\
\hline \multirow[t]{2}{*}{$\mathrm{C}$} & G & $\mathrm{C}$ & AAGGAAAAACUUUGGUUA UCAC & G & $\mathrm{C}$ & $\mathrm{C}$ & NE-1 & & & \\
\hline & & & & & & & & Exp. 1 & Exp. 2 & Total \\
\hline $\mathrm{C}$ & G & $\mathrm{C}$ & AAGGAAAAACUUUGGUUAAUCAC & $\Delta$ & $\underline{\mathrm{U}}$ & $\underline{\mathrm{U}}$ & Recombinant type 1 & 6 clones & 12 clones & 18 clones \\
\hline C & $\underline{\mathbf{A}}$ & C & AAGGAAAAACUUUGGUUAAUCAC & $\underline{\mathrm{A}}$ & $\underline{\mathrm{U}}$ & $\underline{\mathrm{U}}$ & Recombinant type 2 & 0 clone & 1 clone & 1 clone \\
\hline C & G & $\mathrm{C}$ & AAGGAAAAAACUUUGGUUAUCAC & G & $\mathrm{C}$ & $\mathrm{C}$ & Edited type & 4 clones & 13 clones & 17 clones \\
\hline & & & & & & & Total & 10 clones & 26 clones & 36 clones \\
\hline
\end{tabular}

Fig. 3. Sequences of cloned PCR products of DI RNAs derived from cells infected with passage 0 virus sample obtained from NE-1 DI RNA-transfected, MHV-infected cells. MHV-A59, MHV-JHM and NE-1 sequences are also shown for comparison. Nucleotide positions numbered from the 5'-end of the genome are shown above the MHVA59 sequence. Underlined nucleotides indicate MHV-A59-specific nucleotides. The $\mathbf{A}$ nucleotide inserted into the edited DI RNA is indicated by double underlining. The number of clones used for sequence analysis in each of the two independent experiments are listed under Exp.1 and Exp.2.

detected in cells infected with passage 0 virus sample obtained from NE-1 DI RNA-transfected cells, although it was not detected in the NE-1 RNA-transfected and MHV-infected cells. This result suggested that the small ORF present in the original NE-1 DI RNA was changed to the large ORF during DI RNA replication and amplification.

To confirm the change of the NE-1 ORF during RNA replication, the sequence of the DI RNA present in the passage 0 virus-infected cells was examined. Intracellular RNA was extracted at $7 \mathrm{~h}$ p.i. from cells infected with passage 0 virus samples obtained from NE-1 DI RNAtransfected, MHV-infected cells. DI RNA-specific PCR product with the predicted size of 0.96 $\mathrm{kb}$ was prepared. The gel-purifed PCR product was cloned into a plasmid vector and sequenced. This experiment was conducted twice independently, under identical conditions, with virtually no difference in sequencing results (Fig. 3). Sequence analysis of the 36 clones obtained demonstrated that the sequences of DI RNAs in passage 0 virus-infected cells could be classified into two types. Nineteen of the 36 clones had a sequence in which the $\underline{A}$ nucleotide deletion at 
position 376 was repaired. As it is known that MHV undergoes high-frequency RNA recombination $(2,12)$, it seems likely that this sequence alteration was probably caused by RNA recombination between NE-1 DI RNA and MHV-A59 helper virus genomic RNA. The remaining 17 clones had a sequence which differed from the recombinant type: the single $\underline{A}$ nucleotide deletion at position 376 was not repaired and no RNA recombination was observed. However, each of these clones contained an additional $\underline{A}$ insertion 9 nucleotides upstream of the deletion site; this insertion produced a stretch of 6 consecutive A's. This nucleotide addition converted the NE1 -specific small ORF into a long ORF encoding 567 amino acids. These sequence analyses clearly demonstrated that the NE-1 DI RNA sequence was altered by RNA recombination to produce a large ORF. Furthermore, DI RNA species in which an $A$ nucleotide was inserted 9 nucleotides upstream of the deletion site, thus producing a large ORF, also accumulated during replication of DI RNAs.

\section{DISCUSSION}

The present study demonstrated that DIssE-derived NE-1 DI RNA, which had a small ORF as compared to wild-type DIssE, replicated efficiently in MHV-infected cells, suggesting that a large ORF is not necessary for the replication of DI RNA. Analysis of DI RNAs obtained from passage 0 virus-infected cells demonstrated that most of these DI RNAs contained a large ORF similar to wild-type DI RNA. Of this group, approximately half of the DI RNAs contained sequences created by RNA recombination and the remainder contained sequences in which an $\underline{A}$ nucleotide was inserted 9 nucleotides upstream of the deletion site. It is not known whether the addition of the A nucleotide at this specific site on DI RNA occurs during in vtro transcription of NE-1 RNA by T7 RNA polymerase or during replication of NE-1 DI RNA.

Although a large ORF was not necessary for efficient MHV DI RNA replication, our study showed that DI RNAs with the large ORF accumulated during DI RNA replication. Although the mechanism of the accumulation of DI RNAs with large ORF is not clear, several possibilities may be considered. Due to the one-nucleotide deletion, the secondary or tertiary structures of NE-1 DI RNA might differ slightly from those of DI RNAs with the large ORF. It is possible that the MHV RNA replication machinery has a slightly better affinity for DI RNAs with the large ORF than for NE-1 DI RNA, resulting in the preferential replication of DI RNAs with the large ORF. The possible structural differences between these DI RNAs may be caused by the association of DI RNAs with ribosomes. It is possible that nascent positive-stranded DI RNA associates with ribosomes immediately after transcription and the DI-specific protein is synthesized cotranscriptionally. If this is the case, nascent strands of NE-1 DI RNA will dissociate from the ribosome $0.38 \mathrm{~kb}$ from the 5'-end, while nascent strands of DI RNAs with the large ORF are associated with the ribosome to $1.9 \mathrm{~kb}$ from the 5'-end. This difference may result in structural differences between different DI RNAs, and the RNA structure made by the longer association with ribosomes may have a slightly better affinity for the limited amount of MHV RNA replication component. Further studies are needed to determine the role of the DI-specific ORF in MHV DI RNA replication.

\section{ACKNOWLEDGEMENTS}

We thank Susan Baker for the anti-p28 antibody and Sima Vafaee for technical assistance. We thank Jennifer Fosmire for critical reading of the manuscript. This work was supported by Public Health Service grants AI29984 (to SM) and AI16144 (to MMCL) from the National Institutes of Health. MMCL is an investigator of Howard Hughes Medical Institute.

\section{REFERENCES}

1. Baker, S. C., C.-K. Shieh, L. H. Soe, M.-F. Chang, D. M. Vannier, and M. M. C. Lai. J. Virol. 63:3693 (1989).

2. Baric, R. S., K. Fu, M. C. Schaad, and S. A. Stohlman. Virology 177:646 (1990).

3. Fosmire, J. A., K. Hwang, and S. Makino. J. Virol. 66: 3522 (1992). 
4. Jeong Y. S., and S. Makino. J. Virol. 66: 3339 (1992).

5. Lai, M. M. C., R. S. Baric, P. R. Brayton, and S. A. Stohlman. Proc. Natl. Acad. Sci. USA 81: 3626 (1984).

6. Lai, M. M. C., P. R. Brayton, R. C. Armen, C. D. Patton, C. Pugh, and S. A. Stohlman. J. Virol. 39: 823 (1981).

7. Lai, M. M. C., C. D. Patton, R. S. Baric, and S. A. Stohlman. J. Virol. 46: 1027 (1983).

8. Lai, M. M. C., and S. A. Stohlman. J. Virol. 26: 236 (1978).

9. Lee, H.-J., C.-K. Shieh, A. E. Gorbalenya, E. V. Eugene, N. La Monica, J. Tuler, A. Bagdzhadzhyan, and M. M. C. Lai. Virology 180:567 (1991).

10. Leibowitz, J. L., K. C. Wilhelmsen, and C. W. Bond. Virology 114: 39 (1981).

11. Makino, S., N. Fujioka, and K. Fujiwara. J. Virol. 54:329 (1985).

12. Makino, S., J. G. Keck, S. A. Stohlman, and M. M. C. Lai. J. Virol. 57:729 (1986).

13. Makino, S., M. Joo, and J. K. Makino. J. Virol. 65.:6031 (1991).

14. Makino, S., and M. M. C. Lai. J. Virol. 63: 5285 (1989).

15. Makino, S., C.-K. Shieh, J. G. Keck, and M. M. C. Lai. Virology 163: 104 (1988).

16. Makino, S., C.-K. Shieh, L. H. Soe, S. C. Baker, and M. M. C. Lai. Virology 166:550 (1988).

17. Makino, S., L. H. Soe, C.-K. Shieh, and M. M. C. Lai. J. Viol. 62:3870 (1988).

18. Makino, S., F. Taguchi, N. Hirano, and K. Fujiwara. Virology 139: 138 (1984).

19. Makino, S., K. Yokomori, and M. M. C. Lai. J. Virol. 64:6045 (1990).

20. McMaster, G. K., and G. G. Carmichael. Proc. Natl. Acad. Sci. USA 74:4835 (1977).

21. Shieh, C.-K., L. H. Soe, S. Makino, M.-F. Chang, S. A. Stohlman, and M. M. C. Lai. Virology 156: 321 (1987).

22. Spaan, W., H. Delius, M. Skinner, J. Armstrong, P. Rottier, S. Smeekens, B. A. M. van der Zeijst, and S. G. Siddell. EMBO J. 2: 1939 (1983).

23. van der Most, R. G., P. J. Bredenbeek, and W. J. M. Spaan. J. Virol. 65:3219 (1991). 